\title{
GEOPOLÍTICA, MEIO AMBIENTE E ORGANIZAÇÕES NÃO-GOVERNAMENTAIS
}

\author{
Jorge Ulises GUERRA VILLALOBOS \\ Departamento de Geografia, Universidade Estadual de Maringá (Brasil)
}

Neste artigo, que tem por título geopolítica, meio ambiente e organizações não-governamentais, a questão central que interessa-me abordar é a relação existente da geopolítica com esses dois elementos/entidades.

No decorrer deste trabalho, mencionarei três exemplos das relações entre geopolítica e meio ambiente: um referente à questão costa-riquenha (1990), outro ao Santuário Ecológico do Parque Pumalín, no Chile (1996) e finalmente o terceiro exemplo referente aos testes nucleares da França no Atol de Mururoa (1995-1996) e as organizações não-governamentais.

\section{CONSIDERAÇÕES INICIAIS.}

Se bem é certo, o termo geopolítica foi proposto por Rudolf Kjëllen (18641922), advogado e político sueco, quando professor da Universidade de Upsala no ano de 1916, na sua obra $O$ Estado como forma de vida. Dezenove anos antes, em 1897, um geógrafo alemão, Friedirich Ratzel (1844-1904), num livro intitulado Geografia Política, estabelecera, fortemente influenciado pela obra de Darwin, uma análise territorial biologista, na qual o Estado seguia um processo similar ao dos seres vivos. Essa proposta viria a ser a base de uma geografia de Estado (CostA, 1992).

Durante os debates deflagrados a partir desses autores e de suas obras, principalmente no período pré e pós Primeira Guerra Mundial, o conceito geopolítica foi intensamente discutido (COSTA, 1992; TYLOR, 1994; SÁNCHEZ, 1995), não somente de um ponto de vista acadêmico, mas também a partir da perspectiva da aplicação de seus princípios teóricos. Contudo, o debate posterior a essa época, de 1936 em diante, nessa área do conhecimento, foi acompanhado de forte carga histórica negativa, a tal ponto que Vicens Vives (1950), chegou a sustentar a palavra geohistoria como sinônimo de geopolítica, insistindo que utilizando a palavra Geohistória, indicava-se, de maneira decisiva, a atitude científica e neutra dos estudos geopolíticos.

Em parte, como resultado desses temores acadêmicos, a Geografia Política foi consolidando-se como uma área da Geografia, e a geopolítica estabelecia-se em uma estreita relação com a ciência política; porém, como afirmava Marx (1992), a modernidade caracteriza-se por uma constante transformação. Assistimos, nos últimos dez anos, a uma vigorosa e importante retomada da geopolítica dentro do

Polígonos, nº 9, 1999, pp. 205-214. 
âmbito da Geografia e uma aproximação conceitual entre Geografia Política e geopolítica, como demonstra Sánchez ao afirmar que a

Geografia Política [não se entende] exclusivamente como geografia política do Estado, e sim como relações de poder no espaço [uma questão central nos estudos geopolíticos], nas quais, não obstante, a unidade do Estado, assim como suas relações, são muito importantes, mas não sendo essas as únicas relações políticas possiveis (SÁNCHEZ, 1995).

A perspectiva de análise acadêmica presente, distanciada dos interesses imediatos da Segunda Guerra Mundial, tem aproximado os estudos geopolíticos do âmbito da Geografia e penso que o significado negativo dessa palavra, associado principalmente à teorização desenvolvida por Karl Haushofer (1869-1946), parece estar relegado a segundo plano.

Para os acadêmicos, como também para o público geral, isso parece estar manifesto num artigo da Folha de S. Paulo intitulado VÔLEI. Potências passam por transição e têm como desafio provar superioridade sobre 'emergentes' do Leste Europeu. Liga Mundial expõe nova geopolítica. No artigo podemos continuar lendo: A oitava edição da Liga Mundial de vôlei masculino, que tem sua primeira rodada hoje, vai servir para delinear a geopolitica do esporte nos próximos anos (FOLHA, 1997). Essa matéria indica-nos que as questões geopolíticas passam a ser vistas com outros olhos e a estar no vocabulário do dia-a-dia com uma conotação bem diferente daquela de 20 anos antes.

Seguindo esse reposicionamento nos estudos da geopolítica, Taylor (1994) define-a como uma forma concreta de raciocínio que avalia e ordena os lugares em termos de segurança de um único Estado ou de um grupo de Estados. Esse autor reconhece no seu trabalho, dois caminhos nas análises geopolíticas: um do tipo prático, e outro acadêmico ou teórico. Todavia a geopolítica, tanto a de âmbito prático como a de âmbito acadêmico, seria construída a partir de códigos geopolíticos, que são princípios estratégicos que um governo elabora sobre outros Estados para orientar sua política externa (TAYLOR, 1994), sendo que nesses códigos geopolíticos são inseridos os discursos ambientalistas.

Antes de passar aos casos propostos neste trabalho, gostaria de apontar os aspectos que destacarei. Um deles é a importância dos recursos terrestres, cuja exploração pode resultar básica para o desenvolvimento econômico tanto da economia nacional como mundial; outro é a posição geoestratégica dos Estados fora dos seus territórios nacionais, mas ambos relacionados com as questões ambientais.

\section{A QUESTÃO COSTA-RIQUENHA E O SANTUÁRIO ECOLÓGICO DO PARQUE PUMALÍN NO CHILE.}

A questão da Costa Rica pode ser resumida em dois princípios básicos, um como parte da política mundial referente à conservação das florestas tropicais úmidas; outra como área de influência dos Estados Unidos na América Central.

A respeito do primeiro ponto, é interessante lembrar que Mackinder, num artigo publicado em julho de 1943, afirmava a importância das florestas tropicais como 
parte de seu quarto conceito geográfico, sendo essas florestas as que contribuiriam para garantir o equilíbrio e a liberdade dos seres humanos. Se bem é correto, ele pensava na capacidade dessas áreas para o sustento alimentar, não deixando de considerá-las como estratégicas e insinuando claramente a necessidade de sua posse. Entretanto, a conservação e posse das florestas tropicais não estão centradas somente nesse aspecto, e os informes do Banco Mundial (BANCO MUNDIAL, 1991) assim o demostram.

Nas florestas tropicais úmidas o Banco Mundial (1991) adotara uma política cautelosa a respeito da sua exploração, e incentivara os governos a aplicar igual critério. Esse critério, segundo o mesmo Banco, deve-se ao fato de que ainda existem incertezas a respeito da plena valoração dos beneficios ambientais que a própria natureza prevê, e também aos precários conhecimentos atuais sobre os sistemas sustentáveis [...] e aos efeitos irreversiveis da perda das florestas tropicais úmidas (BANCO MUNDIAL 1991). Nessa mesma linha, no entanto, já dentro do âmbito do domínio do conhecimento e controle tecnológico, está o comunicado da Hoechst (La Vanguardia, 1997), que afirma:

Descobriu-se que o veneno de uma cobra [jararaca] do Brasil contém proteinas que intensificam o efeito [das cininas, que é um hormônio que reduz a pressão arterial] produzindo vasodilatação $e$ diminuição da pressão arterial. Cientistas da Hoescht aproveitaram esse descobrimento para sintetizar substâncias do mesmo tipo e convertê-las em medicamento.

Essa notícia confirma que os interesses na biodiversidade das florestas não estão centrados somente na dimensão ambientalista e sim numa dimensão estratégica e comercial.

A respeito do segundo ponto, da posição da Costa Rica e Estados Unidos, podemos citar o trabalho de García (1994), que afirma que os EUA intervêm em áreas da Costa Rica [ não somente como parte da sua política histórica de controle da região centro americana, mas também porque esta ]é rica em biodiversidade, para utilizá-las em beneficio da sua indústria farmacêutica, subtraindo assim uma fonte de riqueza nacional e de novos ingressos.

É importante lembrar que em 20 países, muitos deles do Terceiro Mundo, estão concentradas $85 \%$ das florestas tropicais úmidas.

O "Santuário Ecológico" do Parque Pumalín, é uma área localizada no sul do Chile, na região de Puerto Montt, com 2.750 quilômetros quadrados, o que equivale à área do estado de Alagoas.

Nessas terras existe a última floresta de Alerces do Chile, a qual desde 1995 está nas mãos de um único proprietário, Douglas Tompkins, milionário norteamericano membro do Deep Ecology, organização não governamental ambientalista norte-americana que dá o nome à fundação que administra o parque. $\mathrm{O}$ valor total gasto para a compra da área soma U\$12.000.000.

A área total do parque converte Tompkins no proprietário do maior santuário ecológico particular do mundo, além de transformar um estrangeiro no segundo maior proprietário de terras do Chile, sem que isso signifique algum investimento direto em atividades econômicas.

A discussão que envolve a compra de terras por esse ambientalista não está na 
forma, como asseguram alguns, terem sido estas adquiridas (Tompkins sustenta que comprei um sítio e, quando já estava instalado nele, percebi que era possivel comprar as terras vizinhas), mas sim nas questões que decorrem da posição estratégica do parque.

Sua localização apresenta dois aspectos importantes. O primeiro é que por setenta quilômetros da sua propriedade, na direção leste, o parque limita diretamente com a fronteira argentina, fato que, em princípio, obstaculizaria o controle fronteriço. O segundo aspecto é que, pela posição do parque no sentido norte - sul, este divide o país em duas partes, as quais podem ser reconhecidas como antes do parque e depois do parque, situação que implica um problema de continuidade territorial.

Esse conflito desatou-se publicamente em agosto de 1996, com conotações ambientais, porém, sem dúvida, possui também importantes componentes geopolíticos.

Se para Tompkins seu parque é uma boa ação, para o governo e os militares trata-se de uma questão de soberania nacional, questionada pelos defensores da conservação das florestas da região sul do país (GARCÍA, 1993).

\section{OS TESTES NUCLEARES DA FRANÇA NO ATOL DE MURUROA.}

Nesta penúltima parte do trabalho analisarei mais detidamente esse outro exemplo da geopolítica e do meio ambiente.

As partes envolvidas nessa discussão são variadas, no entanto, penso reconhecer somente as seguintes: o governo francês, executor das provas, Greenpeace, organização não-governamental ambientalista; os habitantes das ilhas da Polinésia francesa que são colônias de França no Pacífico, e que foram diretamente envolvidos nos testes, e outro países que intervêm no debate internacional. Todos esses atores foram movimentados a partir da decisão do governo de Jacques Chirac, tornada pública em 13 de junho de 1995, de reiniciar os teste nucleares na sua possessão do Pacífico Sul.

Essas provas estenderiam-se de $1^{\circ}$ de setembro de 1995 até 31 de maio de 1996, numa série de sete ou oito testes. A retomada das experiências fazia-se depois que François Mitterand interrompera-nas em abril de 1992. Como presidente da França, ele havia autorizado desde 1982 até 1992 oitenta e seis provas nucleares.

Nesse mesmo comunicado, o governo francês comprometia-se a assinar em meados de 1996 o tratado de proibição de todos os testes nucleares, como efetivamente o fez.

A oposição da Alemanha aos testes pode ser resumida nas palavras do ministro das Relações Exteriores Klaus Kinhel, que afirmou Queremos e devemos preservar a amizade franco-alemã e não podemos esquecer o fato de que a França nos ajudou muito no passado sobre questões de seguridade numa Alemanha dividida (La Vanguardia, 1995a). Por outro lado, protestos do governo australiano eram contestados no jornal Le Figaro, que em seu editorial, afirmava que a posição do governo da Austrália estava em parte centrada na dor de consciência que este 
tinha por ter procedido à depuração dos aborígines australianos ${ }^{1}$.

O presidente do Parlamento Latino-americano afirmou em Caracas, antes que os testes fossem realizados, a possibilidade de estudar medidas efetivas contra a França, assinalando a não-compra de produtos franceses como medida possível, tal qual os países do Pacífico estavam fazendo.

A Austrália, nesse momento, havia excluído da concorrência para renovação dos aviões de treinamento para o exército o grupo francês Dassault, e ainda tinha incentivado a campanha das organizações de consumidores para a não-compra de produtos franceses, afetando principalmente o vinho francês, que sofrera na época uma queda de $40 \%$ nas vendas. Por sua parte, a França ameaçava rever os contratos de compra de urânio e carvão que adquirira da Austrália.

Vale lembrar que a Austrália exportava, para França, em 1995, 5,8 milhões de francos e importava 4,2 milhões de francos, o que significava que sua balança comercial era positiva no comércio com Paris, e isso certamente pesou nas discussões pós-testes nucleares.

O governo francês, em 10 de agosto, numa ação para neutralizar as oposições, comunicava em Genebra sua firme intenção de renunciar aos testes atômicos, obrigando, com isso, os outros estados nucleares ${ }^{2}$ (Cf. QUADRO 1)a posicionar-se a respeito. Paris afirmava que depois dos testes do Pacífico, o fim das provas podia ser definitivo e total (La Vanguardia, 1995c), relançando um amplio debate, através do qual pretendia distender as pressões que vinham sendo desenvolvidas contra seus experimentos. $\mathrm{O}$ ministro do Exterior, chega ainda a afirmar que o Atol de Mururoa converteria-se, ou em um centro turístico ou em uma estação de vigilância do meio ambiente.(La Vanguardia, 1995c)

Quadro 1. Explosões nucleares (1945-1995)

\begin{tabular}{llrr}
\hline \multicolumn{1}{c}{ PAÍS } & \multicolumn{1}{c}{ LOCAL } & \multicolumn{1}{c}{ N $^{\mathbf{0}}$} & ANO \\
\hline Estados Unidos & Nevada - Nuevo México & 1.030 & 1945 \\
Ex URSS & Ásia Central & 715 & 1949 \\
França & Argélia- Reggane - Atol de Mururoa e Fangatufa & 204 & 1960 \\
Grã-Bretanha & Nevada - (?) & 45 & 1952 \\
China & Lop Nor - deserto do oeste do país & 44 & 1964 \\
\hline
\end{tabular}

FONTE: La Vanguardia.España, 18 de agosto de 1995, Internacional, p. 3.

É importante destacar que no dia 17 de agosto, no meio de todo esse debate, no lago Lop Nor, noroeste da China, o governo de Pequim realizava sua quadragésima quarta prova nuclear, numa espécie de corrida contra o tempo antes de se reiniciarem as negociações em Genebra para o fim dos testes nucleares.

O experimento chinês recebeu o repúdio público do governo japonês, que pre-

\footnotetext{
${ }^{1}$ El País. «El continente de los niños perdidos: durante años, el Gobierno australiano apartó de sus padres a los hijos de los nativos entregándolos en adopción a familias blancas». España: 27 mayo 1997, p. 72.

${ }^{2}$ Desde o dia 16 de julho de 1945, quando explodiu a primeira bomba atômica em Nuevo México (EUA) até 1995 foram realizados 2.038 provas nucleares.
} 
tendia condicionar os programas de cooperação para o desenvolvimento, ainda que não a parte substancial dos empréstimos (La Vanguardia, 1995c), e do governo norte-americano, que afirmava condicionar sua participação na Conferência da Mulher, que aconteceria em setembro desse ano. Porém o governo japonês continuou com os programas de cooperação, e Hillary Clinton participou ativamente na Conferência da Mulher em Pequim.

No entanto, ante a pressão norte-americana para que outras potências pusessem fim aos testes nucleares, no dia 17 de agosto fizeram-se públicos os resultados das pesquisas que apontavam as experiências radioativas com seres humanos, desenvolvidas pelos Estados Unidos. O estudo indicava que mais de 16.000 pessoas [...] foram utilizadas como cobaias por cientístas dos Estados Unidos para seus experimentos médicos radioativos (La Vanguardia, 1995c), isso desde a Segunda Guerra Mundial até os anos 70. A resposta de Washington foi que todos os experimentos foram desenvolvidos com objetivos médicos (La Vanguardia, 1995c) e que não existiu nenhuma motivação osbcura (La Vanguardia, 1995c).

Durante os meses de agosto e setembro, três frentes de ação tentavam atingir a decisão francesa de retomar os testes nucleares no Pacífico. Uma era a frente liderada pelo Greenpeace, que coletara durante a campanha de desnuclearização 7 milhões de assinaturas. Outra era a frente diplomática que, segundo a França, pretendia atingir sua soberania nacional nas águas territoriais da Polinésia Francesa; somada a isso outro argumento geopolítico, Austrália e Nova Zelândia se opunham, reclamando uma identidade regional da qual a França não formaria parte, e além disso, esses dois países incentivaram o processo de descolonização da região.

A terceira frente era a comercial, desenvolvida através de uma campanha de boicote aos vinhos franceses (La Vanguardia, 1995d).

No dia 2 de setembro, Chirac afirmava que a força de ação nuclear francesa seria importante à medida que a União Européia construía sua defesa (La Vanguardia, 1995e) e a França tinha um papel estratégico básico. O discurso do primeiro-ministro francês da época, Alain Juppé, vinha na mesma direção: a força de dissuasão francesa não é somente a garantia da independência da França; é fundamental para a Europa, para sua segurança e para a paz (La Vanguardia, 1995f). Com essa disposição, Paris insistia na sua determinação, e pressionava pelo silêncio público de seus aliados europeus. Prevaleciam somente as ações contrárias do Greenpeace, da Austrália e da Nova Zelândia, que denunciaria a França ante o Tribunal de Haia em 21 de agosto, tendo como resultado a negação da petição neozalendesa, por tratar-se de assuntos internos da França.

Nesse grupo de opositores integrou-se ativamente o líder do Partido Independentista da Polinésia Francesa, Oscar Temaru, que esperava explorar politicamente (La Vanguardia, 1995f)os testes em Mururoa, além de ser o anfitrião da delegação parlamentar que iria reunir-se em Papeete, capital da Polinésia Francesa.

A presença do líder independentista na campanha ambientalista provocou no dia 2 de setembro, a manifestação de milhares de pessoas a favor da independência da Polinésia em Papeete e pela liberação de Temaru, que tinha sido detido, pelo governo francês. 
A intenção central de Temaru era que no Fórum do Pacífico Sul, que aconteceria em setembro desse mesmo ano, fosse proposta oficialmente a inscrição da Polinésia Francesa na lista dos países a serem descolonizados pelas Nações Unidas (La Vanguardia, 1995f), interesse não somente dos habitantes dessas ilhas, mas também da Austrália e da Nova Zelândia.

Não podemos esquecer que a corrida pelos testes e pelo acordo de Genebra para pôr fim a eles, está em que uns 25 países além dos citados no quadro 1 estão no umbral do armamento nuclear (La Vanguardia, 1995 f). Isso põe em relevo a capacidade de ação do lobby nuclear, o que pode ser visto também através da boa relação dos membros do grupo. A França, para realizar os testes, deve transportar a carga nuclear desde suas bases em território europeu até a Polinésia, e para isso tem utilizado aviões que sobrevoam o espaço norte-americano, evidentemente com autorização do governo de Washington, e quando este se tem negado, os aviões franceses têm voado sobre o Panamá (La Vanguardia, 1995g).

O que a França e a China procuravam, era obter informações para construir o modelo de experimentação em laboratório (Projeto PALEN: Preparação da Limitação de Experiências Nucleares) e depois assinar o tratado de fim dos testes nucleares, o que foi efetivamente realizado em setembro de 1996, quando a Assembléia Geral da Organização das Nações Unidas (ONU) aprovou o Tratado Global que proíbe os testes nucleares. A preocupação francesa era dominar a tecnologia das provas em laboratório que os outros países nucleares ${ }^{3}$ detinham.

O presidente francês, para garantir seu prestígio interno e reafirmar que não tinha esquecido seus compromissos eleitorais, afirmava que não somente era necessário garantir um emprego e um lugar na sociedade [falando para os jovens que participavam dos protestos], mas também garantir-lhes sua segurança (La Vanguardia, 1995h). Ainda lembrou a existência de milhares e milhares de bombas atômicas nos paises da ex-União Soviética e alertou para as crises futuras que estas poderiam trazer (La Vanguardia, 1995h).

A primeira explosão, das sete ou oito prometidas, foi no dia 6 de setembro. Durante o dia 7 foram retirados de Paris três embaixadores, entre eles o da Nova Zelândia e do Chile. A França foi alvo de inúmeras manifestações públicas, entre as mais importantes, as da Austrália, que qualificou o teste de ato estúpido ( $L a$ Vanguardia, 1995i); do Japão, afirmando que o programa de ensaios nucleares afetara inevitavelmente as relações entre Japão e França (La Vanguardia, 1995i), da Rússia, onde o porta-voz de Boris Ieltsin afirmava que o teste francês ameaçava romper o atual equilíbrio nuclear no mundo (La Vanguardia, 1995i).

Todavia, os protestos mais importantes ocorreram na Polinésia Francesa, sob a coordenação dos grupos independentistas, que a partir do município de Faa-á, próximo à capital Papeete, iniciaram uma greve geral. No entanto, todos os discursos independentistas foram mediados pelo discurso ambientalista, liderado pelo Greenpeace a tal ponto que os debates das questões ambientais terminavam, convenientemente, camuflando a humilhação dos polinésios ante a decisão unila-

\footnotetext{
${ }^{3}$ Estados Unidos, Grã-Bretanha e Rússia. Os Estados Unidos teria realizado entre 20 e 40 provas em laboratório. La Vanguardia «Las razones ‘técnicas' de Chirac». España: Internacional, 7 set. 1995 , p. 4.
} 
teral de Chirac de retomar os ensaios nucleares em seus atóis (La Vanguardia, 1995j).

Em meados de setembro, o fórum do Pacífico Sul iniciava-se com uma declaração de rejeição à política nuclear francesa. Novamente Nova Zelândia e Austrália foram os países que fizeram as mais duras críticas à política de Paris, sendo também os países que questionaram diretamente a legitimidade da presença da França na região(La Vanguardia, 1995 m), É importante lembrar que são esses dois países os que têm maior peso geopolítico, e que a presença de uma potência externa em suas áreas de interesses é uma questão conflitiva.

Paris está a 17.000 quilômetros de distância de Papeete, que é a capital da Polinésia Francesa (La Vanguardia, 1995i), e a França dispõe na região de uma zona econômica exclusiva de 4,8 milhões de quilômetros quadrados.

No dia 23 de setembro, na reunião dos líderes da União Européia, as críticas aos testes nucleares franceses pareciam ter chegado ao fim. Chirac afirmava categoricamente que contava com o apoio direto, da Europa, Alemanha, Grã-Bretanha e Portugal; ademais, o chancelher austríaco desculpou-se [dos seus protestos antinucleares numa] longa e confusa intervenção. (La Vanguardia, 1995n).

Gráfico 1. Subscriptores do GreenPeace Internacional (1976-1994).

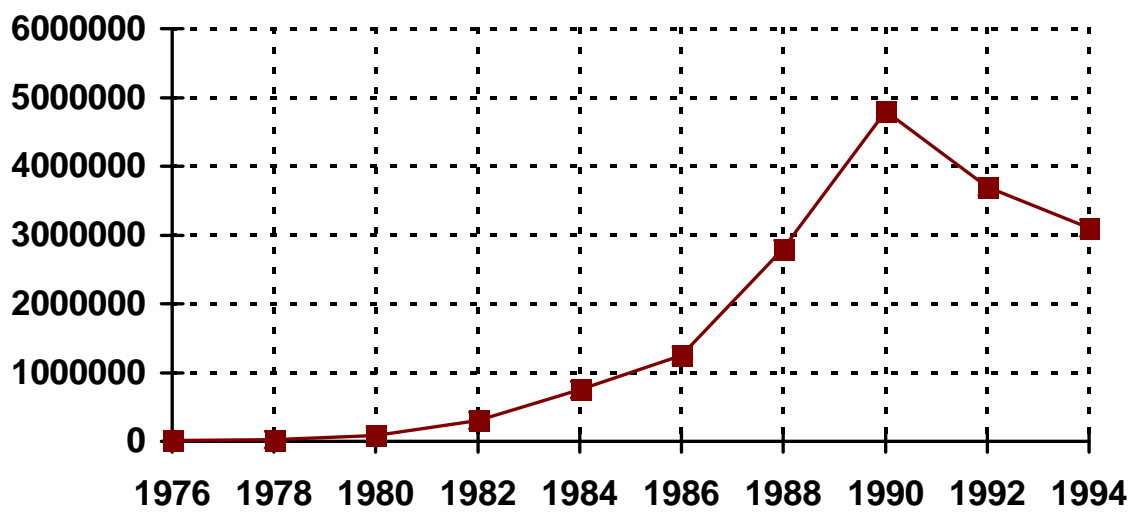

FONTE: La Vanguardia. España: Sociedad, 11 de set. 1995, p. 26

Sem dúvida, Chirac parecia levar na sua administração todas as críticas à política nuclear francesa, o que parece, segundo os dados, incorreto, e as discussões ambientalistas, que davam o tom alto, estavam deixando de lado as dicussões de fundo: a independência da Polinésia Francesa e o controle da Nova Zelândia e da Austrália na região, como aparece manifesto no fórum do Pacífico Sul.

Por outro lado, o Greenpeace, desde sua fundação em 1976 até 1990, tinha aumentado exponencialmente o número de seus subscritores, passando de 10.000 para 4.800.000. De 1990 em diante experimentou um decréscimo significativo 
(cf. GRÁFICO 1), e pelo que tudo indica, a campanha que desenvolveu contra os testes nucleares, estava destinada, em parte, a livrá-lo da situação de crise ao receber uma nova onda de subscritores.

As campanhas dessa organização beneficiam objetivamente os que possuem a tecnologia mais desenvolvida e limpas e que pode resolver problemas ambientais (La Vanguardia, 19951), e na Europa, quem tem essa tecnologia é a Alemanha, o que tem levado a questionar a defesa indireta dos interesses alemães, ainda mais quando o controle da equipe internacional, que define as ações internacionais do Greenpeace, é predominantemente alemã.

\section{CONSIDERAÇÕES FINAIS.}

Para finalizar, direi que a relação entre geopolítica e meio ambiente não pode ser lida de modo linear, tampouco deve-se afirmar que atrás de toda ação existem forças ocultas à procura de benefícios. A questão é muito mais complexa: no caso dos testes em Mururoa, os movimentos estratégicos das potências foram numerosos e contraditórios. Se por um lado, publicamente rejeitavam a experiência francesa, por outro estavam determinados a fechar o clube dos países que detinham a alta tecnologia dos testes em laboratório. O mesmo Greenpeace, argumentando sobre os impactos que a curto prazo causariam a contaminação radioativa, esquecia-se de considerar todos os estudos que demostravam o contrário, além de contribuir para ocultar os problemas políticos da Polinésia Francesa.

Sem lugar à dúvida, uma questão mostra-se interessante em tudo isso: na medida em que uma nova dinâmica mundial se realiza, os interesses por consolidar posições geopolíticas emergem, e para isso, entram em jogo numerosos discursos, entre os quais destaca-se o da proteção do meio ambiente e o das ações de organizações não-governamentais.

\section{BIBLIOGRAFIA.}

- BANCO Mundial (1991): El Banco Mundial y el medio ambiente: Informe sobre la marcha de las actividades. Ejercicio de 1991. Washington, DC, p. 106128.

- Costa, W. (1992): Geografia Política e Geopolítica: discursos sobre o território e o poder. São Paulo: Hucitec.

- El País. «El continente de los niños perdidos: durante años, el Gobierno australiano apartó de sus padres a los hijos de los nativos entregándolos en adopción a familias blancas». España, 27 mayo 1997, p. 72.

- Folha de S. Paulo. «Liga Mundial expõe nova geopolítica» São Paulo, 16 maio 1997, Terceiro caderno, p. 11.

- GARCÍA, J. (1993): «Los problemas del medio ambiente y la ordenación del territorio». In: Medio ambiente y ordenación del territorio. Universidad de Vallalodid, p. 7-31.

- GARCÍA, S. DEL C. (1994): «Medio ambiente y desarrollo en América Latina, problemas sin resolver». Punto de Encuentro, n. 16/17, p. 6 - 7.

- HOESCHT (1997): «Al veneno de una serpiente debemos un medicamento 
providencial». España, La Vanguardia, 31 mayo 1997, p. 5.

- HORN, VON P. (1993): «El acuerdo holandés de desarrollo sostenible con Costa Rica». Madrid, Síntesis, n. 20, jul.dic. 1993, p. 131-146.

- La Vanguardia 1995a: «Alemania descarta de forma definitiva que Chirac vaya a rectificar su política nuclear». España: Internacional, 10 ago. 1995, p. 6.

--- 1995b: «Francia renuncia a realizar más pruebas nucleares después de los ensayos en el Pacífico: París propone impulsar en Ginebra el tratado para la prohibición de toda prueba nuclear». España: Internacional, 11 ago. 1995, p. 4.

--- 1995c: «Nuevos ensayos nucleares en Asia: China realiza otra prueba atómica, ajena al rechazo de sus vecinos». España: Internacional, 11 ago. 1995, p. 3.

---1995d: «El triple frente de la ola antinuclear». España: Internacional, 26 ago. 1995 , p. 3.

---1995f: «Francia ultima la primera prueba nuclear mientras apresa dos barcos de Greepeace». España: Internacional, 2 set. 1995, p. 6.

---1995g: «La BOMBA Chirac». España: La Semana, 3 set. 1995, p. 4.

---1995h: «Dos barcos de Greenpeace tomam el relevo para perturbar la inminete prueba en Mururoa». España: Internacional, 5 set. 1995, p. 6.

--1995i: «Chirac anuncia que Francia acabará las pruebas nucleares antes de lo previsto». España: Internacional, 6 set. 1995, p. 6.

---1995j: «La prueba nuclear francesa desata indignación y condenas mundiales». España: Internacional, 7 set. 1995, p. 3.

---1995k: «Las razones 'técnicas' de Chirac». España: Internacional, 7 set. 1995 , p. 4.

---19951: «La protesta antinuclear enciende la revuelta callejera en tahití». España: Internacional, 8 set. 1995 , p. 3.

---1995m: «La organización espera que las últimas acciones le permitan recuperar socios». España: Sociedad, 11 set. 1995, p. 26.

---1995n: «El Fórum del Pacífico revisará sus relaciones con Francia». España: Internacional, 15 set. 1995 , p. 9.

---1995: «Chirac supera las críticas de sus sócios a la reanudación de las pruebas nucleares». España: Internacional, 24 set. 1995, p. 6.

- MACKINDER, H. O Pivô central da História.

- SÁNCHEZ, J. (1981): La geografia y el espacio social del poder. Barcelona: Los Libros de la Frontera.

--- (1995): Geografia Política. Madrid: Sintesis.

- SANTANA, Déborah (1996): «Geographers, colonialism, and development strategies: the case of Puerto Rico». Londres, Urban Geography, n.5 , v. 17, p. $456-474$.

- SOUZA, H. De (1992): «O papel das ONG’s e da sociedade civil em relação ao meio ambiente». Planejamento e Políticas Públicas, Brasilia 7, p. 39-56, jun.

- TAYLOR, J. (1994): Geografia Política: economía mundo, Estado-nación y localidad. Madrid: Trama Editorial.

- VICENS VIVES (1950): Tratado geral de geopolítica. Barcelona: Universidad de Barcelona, p. 7. 